REVISED: 14.08.2017. Accepted manuscript for publication in: Medicine, Health Care and Philosophy.

\title{
Let Us Talk about Eggs! \\ Professional Resistance to Elective Egg Vitrification and Gendered Medical Paternalism
}

Judit Sándor, Lilla Vicsek, Zsófia Bauer

\begin{abstract}
In this paper, by applying a feminist bioethical perspective, we identify a new form of medical paternalism that still shapes contemporary legal policies on human egg cryopreservation performed without medical reasons. The fear of negligent, careless women who opt to delay their pregnancy for mere convenience is a widely known gender biased stereotype. Nevertheless, the opinions and judgments of medical professionals on this issue have not yet been sufficiently explored by in-depth research. In this essay, therefore, first we look at the broader bioethical, legal, and social aspects of human egg cryopreservation. In the second part of the paper we discuss a unique qualitative study conducted with professionals working at Hungarian IVF clinics. We argue, based on a bioethical analysis of the collected data, that when new reproduction technologies provide opportunities for women to widen their range of reproductive choices, the traditional forms of medical paternalism can be reinforced by gendered paternalism, as well. We identify several elements of gendered paternalism that characterized the attitudes of the IVF staff and discuss the professionals' resistance to elective egg freezing and vitrification of eggs for the future (EVF). We conclude by suggesting directions for future policy. Although we focus on the Hungarian case in this paper, we are aware that similar attitudes can be observed in some other countries where this technology has become available and requested by women, but where they also face difficulties in their access to it.
\end{abstract}

\section{Introduction}

Assisted reproduction has undergone major changes since 1978, the birth of the first "test tube baby" and the success rate of the growing variety of techniques and methods have significantly improved over the past couple of decades. Reproduction clinics are now able to freeze both embryos and sperms, and to perform intracytoplasmic sperm injection (ICSI). As numerous pre-implantation tests were gradually introduced, the success rate of in vitro fertilization (IVF) has improved. Moreover, it has also become possible to screen embryos for certain serious diseases and the timing of reproduction 
has become also negotiable-at least through sperm cryopreservation. Nevertheless, the feminists' desire to liberate women from the constraints of the ticking biological clock has never been realized. Due to the difficulties and the high costs of the egg freezing process, as well as to the potential risks of damaging the egg during the procedure of thawing, it had taken a long time before the technique was finally introduced. However, even after the procedure itself became safe enough for clinical use, the very idea of egg freezing remained a taboo for a long time in many countries throughout the world.

In this paper we explore the reasons behind the prevailing reluctance to accept the various techniques of egg cryopreservation and analyze the cultural and political biases behind the medical arguments for opposing the widespread application of this procedure. Medical paternalism has been an influential and standard model of the doctor-patient relationship before patients' rights were generally adopted and enforced in many countries. As Gerard Dworkin (1976: 185) described in his work on 'paternalism' as an interference with a persons' liberty of action, and where the justification for this interference is the claim that it is good for the persons whose rights have been restricted. Needless to say that different forms of medical paternalism can be still found worldwide even nowadays, reflecting also social and cultural differences but here we identified a specific form of gendered medical paternalism which provokes a much wider interference with autonomous decisions by female patients.

We will claim that this form of medical paternalism is a discourse deeply embedded in societies where women are expected to give birth to as many children as biologically possible and then spend most of their time raising them. This gender bias is especially strong in countries with pronatalist policies. We explore the case of Hungary to develop our position on how gendered medical paternalism slows down the adoption of egg cryopreservation as an acceptable assisted reproductive technique. In this paper we do not intend to settle the moral debate on egg cryopreservation. Instead, we want to show that various gender-based stereotypes inform the positions in this debate: taken-forgranted and normalized views on the role of women in society, their supposedly 'natural' life cycles, the negative portrayal of the so-called 'careerist woman', and so on. These stereotypical images do not allow a fair and equal treatment of patients. We argue that not only medical paternalism and pronatalism, but also deeply entrenched gender biases inform the ethical, legal, and professional norms that treat egg cryopreservation differently from sperm cryopreservation or ICSI.

The dominant moral discourse emphasizes the importance of an ideal maternal age-not making a difference between the capacity to raise children and the capacity to provide viable eggs for procreation-and claims that family should be preferred over career in a woman's life. However, 'careerist men' are not chastised for postponing their decision to have children, and no one points out the responsibility of aging fathers when the causes of low fertility are discussed. As a result, the introduction of the egg cryopreservation technique is vehemently criticized on moral grounds and the legal argumentations draw from the existing gender stereotypes.

In this research, therefore, we wanted to see how gender-based stereotypical attitudes and arguments appear in professional judgments by those who offer in vitro 
services. Most of the interviewees stated that egg cryopreservation merely serves the 'delay of pregnancy' - and alternative reasons behind the decision, such as not having a suitable partner for co-parenting while securing capacity for procreation, were rarely mentioned. Thus, when medical professionals present their entrenched moral positions as unalterable biological facts, then we can speak of 'gendered medical paternalism'.

\section{Elective Egg Vitrification for the Future (EVF)}

At first it is important to observe that medical and scientific literature is not always consistent in using the terms 'egg freezing', 'cooling', and 'oocyte cryopreservation'. In this article we do not want to engage in a medical terminological debate. Therefore, we will simply use 'egg cryopreservation' or 'oocyte cryopreservation' as an umbrella term, and make a distinction between the traditional procedure of 'slow freezing' and the more recently developed 'flash freezing' technique or 'vitrification'. Oocyte cryopreservation, therefore, is aimed at 'saving' the eggs of reproductive-age women for later periods in their life following the natural or artificial depletion of their ovaries in order to maintain the reproductive function. The first successful birth from pregnancy conceived from a frozen egg (after its thawing, fertilization, and implantation) was reported in 1986. Over the three decades since this pioneering case, egg freezing and thawing has become a routine method in the embryological laboratories of assisted reproduction units. The development of cryopreservation methods from 'slow freezing' technologies to vitrification has shown significant improvement in the chance of oocyte survival without damage to their structures. For example, Fadini et al. (2009) compared 286 cases of slow freezing cycles to 59 cases of vitrification cycles, and found that vitrification provided higher survival $(78.9 \%$ versus $57.9 \%)$, pregnancy $(18.7 \%$ versus $7.6 \%)$, and implantation rates (9.3\% versus $4.3 \%$ ) compared to slow freezing (Boldt 2011). Moreover, according to The Practice Committee of the American Society for Reproductive Medicine and The Society for Assisted Reproductive Technology (2013), pregnancy rates of using frozen eggs are similar to those using fresh ones.

Another distinction is even more relevant for our study. In the literature a difference is often made between egg cryopreservation for medical purposes and for non-medical purposes. The former is based on a medical indication: it is recommended for women who are facing fertility decline or damage to their oocyte because of an illness or an invasive medical treatment. The latter is considered to address situations in which women decide to "postpone" childbirth because of difficulties in partner selection, or because of conflicting work obligations, extended education, lack of partner, or psychological difficulties (such as posttraumatic conditions, the loss of a child or a partner). In these cases egg cryopreservation offers women a chance to preserve their eggs until a time when they feel ready to have a child (Baldwin et al. 2014). This technology would give a second chance for women: the chance to decide to voluntarily store their eggs and use them later when they can conceive a child (Goold and Savulescu 2009). Recent medical and social scientific articles refer to the process as 'social egg 
freezing', 'social freezing', 'non-medical egg freezing', or 'elective egg freezing' (Goold and Savulescu 2009, Mertes and Pennings 2011).

In this article we use the term 'elective vitrification of eggs for purposes of reproduction in the future' (in short, 'elective egg vitrification for the future', or EVF) to make a clear distinction between the older cryopreservation technique of egg freezing and the present cryopreservation procedure of vitrification. However, we do not apply the term 'social' to avoid the stigma that the adjective 'social' (as opposed to 'medical') represents. Though EVF is not any longer an experimental procedure, in many countries it is still not available to women, including Hungary-where medical egg freezing is legal and an option available for women.

As mentioned earlier, oocyte cryopreservation for medical purposes has caused significantly less controversy in the scientific community than egg cryopreservation for non-medical reasons. The growing body of theoretical articles shows that opinions towards EVF are polarized: there is debate on whether the elective procedure is safe or ethical, or should even be legal (Bernstein and Wiesemann 2014). Some authors see elective freezing and vitrification as an opportunity and a source of liberation and selffulfillment for women (Inhorn 2013); others are more skeptic and believe that elective egg cryopreservation could lead to further medicalization of reproduction, may generate inequalities and may even further the growing tendency of pregnancies late in life, instead of providing a solution (Soliman et al. 2012; Cattapan et al. 2014; Mohaparta 2014). Mertes and Pennings (2011), as well as Lockwood (2011), highlight the problem that women chose to cryopreserve their eggs at a sub-optimal age, and suggest that there would be fewer risks (both physical and ethical) involved if the elective cryopreservation took place at a younger age. Some studies have found that the average age for women undergoing the vitrification was thirty-eight (Hodes-Werts et al. 2013, Baldwin 2014 quoting Schuman 2011 and 2012). The American Society of Reproductive Medicine, the European Society of Human Reproduction, and the American Society of Clinical Oncology all recognize oocyte cryopreservation as an accepted method for fertility preservation in cancer patients, but do not encourage the same technique for EVF.

\section{Looking at the Wider Social Context}

Women who consider cryopreservation their eggs are often assessed or judged in isolation from the wider societal issues. Longer education and single parenthood should not be regarded merely as a gendered phenomenon. Postponement of first births is a prominent characteristic of fertility patterns in many societies globally. Delayed motherhood presents a problem in many European societies, where couples are increasingly faced with problems related to age-related fertility decline. Fertility postponement can result in less children being born, couples having less children than intended, and in an increase of unintended childlessness (Sobotka 2004; Szalma and Takács 2016). Delayed parenthood is a result of fundamental social, economic and cultural transformations. Various studies have shown that factors such as increased 
educational attainment; increasing female labor market participation and growing investments in career development; uncertainties surrounding employment; difficulties of reconciling work with motherhood; widespread use of contraceptive devices such as the pill; changes in partnership patterns and of social norms on parenthood-these can all contribute to a later timing of childbirth (Sobotka 2004).

Some have argued that the public understanding of biology and technology may also influence timing. Research shows that there are misperceptions about age-related fertility decline and in the lack of more accurate information about it there is false hope that IVF can overcome the age problem (Gossett et al. 2013, Hashiloni-Dolev 2011, Mac Dougall et al. 2012). Results of the small sample research of Mac Dougall et al. (2012) suggest that for some women knowing more information on age-related fertility decline and the limits of IVF in helping with this issue could result in modified strategies and earlier timing of childbirth.

Postponement of childbirth is characteristic of fertility patterns in Hungary as well: the average age of first-time mothers was 27.7 in 2014. This average is somewhat lower than the OECD-25 average for first births, which stands at 28.9 years for women (OECD 2016). The average age of first-time mothers is connected to educational attainment, in case of those with a tertiary degree the average age is much higher than for those without. Women who have completed higher education are at higher risk for age-related infertility problems.

Hungarian society is characterized by conservative gender roles (Scharle 2015), and being pronatalist in general (Szalma 2010). A qualitative study found that fertility myths and technology myths inform the arguments of many of the interviewed female university students, and many students had a misperception of the rate of age-related fertility decline as well as they resisted the idea that this problem can ever apply to them, and were excessively positive of how IVF can help (Vicsek 2017).

Concerns and even worries about population decline are a strong characteristic of fertility and reproduction debates in Hungary. The current conservative government, as well as the Hungarian Round Table on Demographic Issues, espouses a pronatalist ideology and has repeatedly emphasized that one of the serious problems of Hungarian society is that not enough children are born and the average fertility rate is low. However, the topic of infertility seems to be largely missing from this discourse, and the blame is put on the women or women's education or their ambition to work and have a career.

In addition to reviewing the literature we also developed a case study and interviewed medical doctors and biologists at infertility clinics in Hungary. At the same time a policy debate was conducted at the Human Reproduction Commission on the possibility of allowing the procedure of elective egg cryopreservation.

\section{Hungarian Legal Environment and Legal Policy Debate on Elective Vitrification}

In 1997 a major legal reform was conducted in Hungary in the field of health care law. As a result, a new, comprehensive Health Care Act was adopted (Act No CLIV of 1997 on 
Health Care), including first time in the Hungarian legal history specific patients' rights and in a specific chapter dedicated to various legal issues raised by assisted reproductive technologies. Under Section 174 (2) of this Act CLIV of 1997 on Health, "On medical grounds and on recommendation of a specialist physician or when otherwise requested for cause, facilities may accept deposits of reproductive cells from persons in possession of full disposing capacities for frozen storage to be used by the depositor at a later date (reproductive cell deposits)." In other words, the cryopreservation of reproductive cells, including eggs is allowed by the Health Act for the purpose of the depositor's own reproduction later in life. However, Minister of Welfare Decree No 30/1998 (VI. 24.) NM on the Rules of Special Procedures for Human Reproduction and on the Detailed Rules of Use and Freeze Storage of Reproductive Cells and Embryos, although it is of a lower level than an Act of Parliament, has interpreted this provision of the Health Act in a restrictive way. Annex No 4 to Decree No. 30/1998 (VI. 24.) NM (as amended by Section 7 and Annex 2 Point 7) contains indications for the freeze storage of reproductive cells and embryos as well.

In the Annex the following specific indications are listed for the freeze storage of female reproductive cells: (a) in the case of female reproductive cells frozen for the purpose of the patient's own reproduction, prior to introducing a potentially gonadotoxic treatment for neoplastic diseases; (b) in the case of genetic mutation factors (such as BRCA 1 and 2), where the risk of ovarian or mammary carcinoma is very high at a young age and, therefore, elective oophorectomy is to be performed at a young age; (c) in the case of severe endometriosis, where there is a danger of ovary removal becoming necessary; and (d) in the case of individuals employed in a hazardous, particularly hazardous, or health-damaging work environment if the hazards of work may jeopardise the individual's fertility.

It is allowed to freeze eggs for the purpose of the patient's own reproduction in the case of IVF-ICSI treatments where the applicant couple requests for ethical reasons that a number of female reproductive cells less than the number aspired be fertilized as well as in those cases of IVF-ICSI treatments where the number of sperms available is less than the number of eggs aspired. In other words, the annex to the above Decree mentions only medical indications for the cryopreservation of eggs, while sperms may be stored for longer periods of the husband's absence. The term "indication" shall, however, not necessarily mean exclusivity. There is only a single restrictive provision in the Decree, contained in Annex 6, which lays down a mandatory rule of law rather than a recommendation: "No female reproductive cells may be stored if according to the expert opinion delivered by a medical consultant, aspiration would not have any good result."

Consequently, the legal regulations in force in Hungary are related, first of all, to the former egg freezing technologies rather than to vitrification, and the enforcement of the provisions of the Health Act is disproportionately limited by its executive decree. It would, therefore, result in discrimination if only sperms were allowed to be stored for reasons other than medical indications - while the same practice was prohibited in the case of eggs (Sándor 2015). It is also true that there used to be medical reasons for this 
restriction, as before the widespread application of vitrification, the chances of freezing and successfully thawing human eggs were very low.

In 2015-2016 at the Hungarian Human Reproductive Commission (a subcommittee within the Hungarian National Research Council) a debate was launched on a proposal to include vitrification into the list of the legally accepted procedures of assisted reproduction, as well as to extend this option to vitrification for non-medical indications, as well. In the debate many arguments were examined that can support the caution when non-medical egg vitrification is regarded as a fertility preservation method. It is an important ethical and family policy aspect to avoid the skipping of generations, i.e. reproduction should, as far as possible, take place within the generation concerned, giving a chance for the parent(s) to raise their child reproduced artificially. In comparison to other reproductive procedures, vitrification does not involve substantial medical risks and the misconceptions concerning the efficacy of reproduction at a later stage in life can be countered by providing evidence-based and unbiased information on the expected outcome.

\section{The Role of Reproductive Rights in the Debate}

Important arguments in favor of EVF can be made on grounds that it enhances the reproductive freedom of women and acts as a 'gender equalizer', giving women the opportunity to delay their parenthood-which is already possible for men (Goold and Savulescu 2009, Patrizio et al. 2016).

It is now a widespread experience in European societies that the urge to create the conditions necessary for parenting-completing university studies, looking for a job, looking for a life partner-most probably takes place at around 30 years of age for those with a tertiary degree. As many doctors warn of the dangers of childbearing when the mother reaches the age of 37-38, in their view there remains only a small window of opportunity for educated and employed women to give birth to a child when it is still considered the safest up to the age of 35 to 36 years.

Consequently, there is an average time span of five to eight years open for these women to start a family. However, there are a lot of incidents that may happen during this short timeline, such as illness, family tragedy, loss of job, health complications, spontaneous abortion, psychological trauma, divorce, difficulties in establishing a relationship, or relationship dissolution, not to mention infertility problems when, in principle, everything is granted and yet the couple fails to have a child. It is this period when working people in the prime of their lives, holding a diploma and also having some career experience are expected to be the most productive at work. Securing motherhood from a technological aspect would be highly beneficial for this reason, too, as it is very easy to miss these few years. In contrast, a man has very good chances to become a father at the age of 50 to 55 as well, and sperm freezing has also become a routine process by now. This way, the period until a man can become a father while being able to take part in raising the child has become significantly extended. 
In this context elective egg vitrification could diminish the inequality in access to employment and in the difference in reproductive life span between women and men. If human eggs-which might be called the "Holy Grail" of reproduction as it is more difficult to harvest them than the sperms; the technology requires a hormonal treatment and invasive intervention; they are "produced" only for a limited period in life; and there is a high demand for them-could be stored in a good condition and at a reasonable price for the purpose of future reproduction, this relatively short time span which allows possibilities for reproduction after creating the necessary conditions could be extended, and women could be liberated from the stress of the biological clock constantly ticking into their ears.

However, we may observe that medical paternalism and gender bias joins each other to sweep away these high hopes. This combination can also be detected in many similar debates, be they on abortion or contraception. While reproductive rights are generally viewed as empowering, in the case of certain reproductive technologies (such as the freezing of eggs and sperms) women are treated differently than men. It is clear that international human rights and ethical norms are against the discrimination based on gender, and would not allow the contrasting interpretation of reproductive rights originating from deeply ingrained gender biases.

The CEDAW Convention, for example, states that Parties shall take all appropriate measures to eliminate discrimination against women in all matters relating to marriage and family relations and in particular shall ensure, on the basis of equality between men and women. Furthermore, they shall enjoy the same right to freely choose a spouse and to enter into marriage only with their free and full consent. Under Article 16 of the Convention on the Elimination of All Forms of Discrimination against Women (CEDAW), men and women shall have "the same rights to decide freely and responsibly on the number and spacing of their children and to have access to the information, education and means to enable them to exercise these rights."

From the perspective of moral consideration, one of the most important problems is the prevalence of withholding relevant information that could better correspond to the women's needs-so it is time to change the approach: 'Let us talk about eggs'. As the capacity for viable egg retrieval and the capacity of child delivery is different in the case of women, they should be informed about the limited capacity for egg retrieval in a certain age. As we have seen, however, a similar information deficit can be observed in many parts of the world, and many women are misinformed about the correlation between fertility and age (Mac Dougall et al. 2012). Therefore, looking at this question more closely, what has been proclaimed far and wide about 'delaying' maternity or about the 'career desire' of women is nothing else than sheer sexual discrimination or mistaken and/or deficient information about infertility.

It is also obvious that with proper alternative technical solutions being available, it would be improper to force single women to have their eggs fertilized by way of unknown sperm donors instead of allowing them to bank their eggs to preserve the chance that they might have children from eligible future partners. 


\section{Overview of Empirical Studies on Egg Cryopreservation}

Several pieces of research that have studied women who have undergone the procedure or were on a waiting list for it found that in many cases the dominant motivation for storing the oocytes was to increase chances of having a child together with a partner, citing delaying childbirth due to lack of finding the right partner (Waldby 2015, HodesWertz et al. 2013, Stoop et al. 2014). In the US research of Hodes-Wertz et al. (2013) overwhelming majority (88\%) of the 183 patients in the sample reported delaying childbirth due to lack of finding the right partner-only a fourth of them cited career advancement, and even less (15\%) delayed conception because of financial constraints. Most patients ranked future fertility higher on their agenda then career, and this characterized all age groups. Stoop et al. (2014) argue that the main reason for choosing elective cryopreservation for the patients questioned in their sample was to have time to find a suitable partner (49\%) - to have "insurance" (65\%), and to feel that they have exhausted every existing opportunity and not feel regret (32\%). The research of Vallejo et al. (2013) also found that the patients they examined expressed feeling pressures from their biological clock-and also viewed egg banking as a type of insurance policy. Waldby (2015) talked to 15 professional class women who have banked their eggs. For these women EVF was seen as an opportunity to synchronize their biological clock to the rest of their lives-to "other timelines in their life-course" or to "bank time" (Waldby 2015: 475).

Surveys on public attitudes show, that elective egg cryopreservation is viewed more negatively than medical egg cryopreservation; and that the majority of the women in the examined societies-which included Sweden, Belgium, US, Singapore-would not partake in the procedure themselves, or are uncertain (Lallemant et al. 2016, Lewis et al. 2016, Stoop et al. 2011; Hoodes-Wertz et al. 2013; Tan et al. 2014, Wennberget al. 2016). In a small scale study for her MA thesis Keglovits (2015) studied Hungarian women's attitudes towards egg cryopreservation with the help of four focus groups. Her results show the respondents accentuated its unnaturalness and its potential manipulative nature-they did not see it as a way for women to level out their career opportunities even if the procedure was provided as an incentive from companies.

Hardly anything is known about how health care professionals view egg cryopreservation. Vallejo et al. (2013) in their quoted US research with patients also conducted a small sample survey research with 18 health care providers. The majority of the 18 professionals considered the best age for undergoing cryopreservation to be under 35, and that the mean upper limit age "accepted for this procedure" was 39.9 years. A recent study employing online survey by Yu et al. (2016) found that obstetrics and gynecology residents had misconceptions of age-related fertility decline and success rates of assisted reproduction. Part of them overestimated the ages where there is a slight and where there is a marked decline in fertility, and most of them overestimated the success rates of IVF. Only one fourth of the 238 respondents claimed to be 'familiar' or 'very familiar' with oocyte cryopreservation-whilst the majority of the respondents worked at institutions which there was a possibility for patients to undergo this 
procedure. Besides low level of knowledge, residents also showed reluctance to discussing this issue with their patients: only around four tenth of them believed that obstetricians and gynecologists should initiate discussions regarding the procedure with their patients. Even in case of a scenario when a patient would be 35 and telling them of wanting to have a career first, less than half of the respondents answered that they were 'likely' or 'very likely' to initiate a discussion on EVF.

\section{Opinions on Elective Egg Vitrification by Staff Members of Hungarian Infertility Clinics}

We conducted a small-scale empirical study to investigate how doctors and health care workers react on the idea of egg vitrification for the purposes of future reproduction. In our research twelve semi-structured interviews were conducted with professionals at Hungarian infertility clinics. We aimed for a diverse sample that is heterogeneous with respect to occupation, clinic type, age, and gender.

Characteristics of the interviewees are shown in Table 1.

Table 1. List of interviewee characteristics

\begin{tabular}{|c|l|l|l|}
\hline Initials of Name $^{1}$ & Sex & Age group & Occupation $^{2}$ \\
\hline 1. A.A. & Female & $40-59$ & lab assistant \\
\hline 2. Dr. K.I. & Male & $60-$ & gynecologist \\
\hline 3. D.A. & female & $40-59$ & lab assistant \\
\hline 4. Dr. E.A. & female & $25-39$ & gynecologist \\
\hline 5. G.B. & female & $25-39$ & lab assistant \\
\hline 6. L.R. & Male & $40-59$ & embryologist \\
\hline 7. M.K. & Male & $40-59$ & embryologist \\
\hline 8. M.U. & female & $25-39$ & Nurse \\
\hline 9. N.D. & female & $60-$ & Nurse \\
\hline 10. Q.J. & female & $60-$ & embryologist \\
\hline 11. R.A. & female & $40-59$ & embryologist \\
\hline 12. Dr. R.F. & Male & $40-59$ & gynecologist \\
\hline
\end{tabular}

1 The initials have been changed to protect anonymity.

2 More information is not given about the sample to protect anonymity of the interviewees and the clinics involved. As Hungary is a small country, giving even a few bits of information on the clinics could easily lead to the clinics and interviewees to be recognizable.

Interviewees provided their written consent to the interview. Interviews lasted from 30 minutes to an hour. They were conducted by two of the authors of this article, touching upon the following topics: their general opinion on EVF; what do they regard as advantages and disadvantages of EVF; who do they think would utilize EVF; what do they think are causes that make people chose EVF and how do they evaluate these causes; do they think that conditions should be attached to the applications for EVF 
procedures and if yes, then what (for example age limits); would they support state funding of the procedure; and what kind of information would they recommend to be circulated in connection with EVF.

The interviews were transcribed, the transcripts then analyzed with the help of NVivo software. An inductive coding was established and qualitative thematic analysis was conducted building on procedures Braun and Clarke (2016) recommend. In case EVF will be approved in Hungary, infertility clinic staff will be the one providing it, thus it is an important issue how they view this procedure. The possibility of EVF could contribute to generating more work and thus profit for the clinics. On the other hand, Hungarian society has traditional views with respect to gender roles, family, ideal timing of birth of the child (Scharle 2015, Paksi and Szalma 2009) and some aspects of the use of EVF might be thought by some to go against these conservative gender norms

\section{Findings of the Empirical Study}

Most of the interviewees viewed EVF unfavorably. Many of the interviewees articulated a negative opinion of elective egg vitrification from the beginning of the interview; some of them were vehemently against it. All those who were against EVF regarded it primarily as a way to postpone having a child to an age of "older women." They either emphasized that at the time the eggs are to be frozen the women would be already beyond the "optimum" age or they would be "too old" when the eggs are used for IVFand this was regarded negatively by them. Attitudes against EVF were also intertwined with anti-careerist sentiments toward women, as career recurrently came up in their arguments as primary cause for utilizing EVF.

"Freezing gametes so that people could work even more and then after the age of 40 would return and ask me to create a child from their stored gametes? I do not support this idea. I think we should cryopreserve eggs only when we have good reasons for doing that, when there is a medical reasons for this procedure. I dislike the idea that a woman who is 25 years old would like to cryopreserve her eggs because she wants to build a career." (A.A.)

Those who expressed positive attitudes towards IVF the beginning of the interview (a third of the interviewees) - tended not to connect IVF so much with necessarily cryopreserving eggs in the middle or second half of the thirties and using them in the 40 s, but sometimes talked about either vitrifying it earlier or using it earlier. Two interviewees emphasized that because of age related fertility decline just as it is good to have sperm stored in the sperm bank from young age, it could be useful for young women to get their eggs frozen as a safeguard from the twenties. Later during the interviews it was apparent that even those who expressed opinions in favor of EVF in the beginning would feel more comfortable with a younger age group utilizing the method, and that almost all of these few clinicians would even restrict the use of EVF to a younger demographic, such as maximum age of 35 for the extraction of the eggs, etc. (see part of the analysis on age limits and state funding). 
In contrast to EVF, egg banking due to an existing medical problem-such as before chemotherapy-was seen unanimously in a positive light. Two reasons could be discerned for this difference between opinions on the two kinds of egg cryopreservation. On the one hand, having illness as a reason was supported more. Even in case of those who expressed positive attitude towards EVF, turning to egg banking because of medical reasons was regarded to be a more legitimate, important reason, contrasted with having EVF, which was more regarded as a mere convenience. Also the medical reason was seen to be beyond the women's choice, whereas the situation the woman was in because of which she wanted EVF was perceived to be the woman's own choice: the underlying conceptualization of these women being, that they could have a child at that time, but they do not want to, rather they decide to postpone it. It seems that in the respondents' conceptualization of women utilizing EVF the dominant underlying question is why are they not having a child earlier when they could do it (if they did not focus on their career). So instead of seeing EVF as a choice to have a child, it is seen as a decision not to have a child at a time point which is considered proper, as a postponement. Instead of conceptualizing these women as wanting children so much in their life course that even turn to EVF, the emphasis for the interviewees was more on the postponement, which act itself was rated negatively by many.

Another argument on the difference in the favoring of cryopreservation for medical reasons versus non-medical reasons was related to the issue of efficiency. One of the objections against EVF was that it was not efficient enough. This was perceived negatively for several reasons-such as giving false hopes to the clients-which will be discussed later. However, this failure to be 100 percent successful in securing a baby was not seen as a strong enough reason against medical egg cryopreservation as it was argued that in this situation, there is "no other choice", even if it is not 100 percent sure, at least it gives a chance.

Whilst the Hodes-Wertz (2013) study had found that in their sample an overwhelming majority of women turned to EVF because of not finding the right partner, in our interviews work related reasons featured most prominently with the clinician professionals as cause for postponement of childbearing/utilizing EVF. Interviewees connected these causes primarily to career and careerism of the women, one respondent also mentioned job insecurity. Focusing on a career in case of a woman was often viewed negatively, as career and family or career and child were seen to be two options which exclude each other for a woman and negative stereotypes of careerist women were brought into the discussion.

In this rhetoric often two types of 'careerist' women were articulated: one who as blamed for not caring enough to have a child, regarding children as a "hobby", a whim, with negative references to current female patients at the infertility clinic who scheduled their IVF around their work appointments. The other type was seen to be too late in realizing the importance of wanting to have a child and then going overboard with focusing too desperately to have a child-again references to current experiences with patients at the clinic were voiced. Whilst empathy was not apparent in the interviews in these cases, several interviewees brought up cases when somebody whom 
they regarded as "older" wanted to have a child after losing their own child in a tragic way (accident or illness). This was considered a legitimate and supportable reason to want to have a child at that age and feelings of empathy were emphasized towards these women-in contrast to career reasons.

"There is the type of patient that you root for... who has a sad story, like her child has died in an accident, so you root for her. However, among the 44-year olds there are many stories, some of them did not care before, did not care to have children, and now realize that there is no child under the Christmas tree this year, and then she decides that she has to come to this treatment..." (Q.J.)

Other causes for postponement of childbirth mentioned less frequently included: difficulties with finding a partner, not being mature enough to become a mother yet, the longer duration of education, not having enough money, and just delay pregnancy for convenience, out of a whim, doing something because of it being trendy. One participant connected taking the procedure with psychological problems.

It was interesting to observe during the interviews that if the postponement of childbirth was discussed in general terms, as a trend in society, the 'careerist' stance of women was seen to be the culprit, and negative stereotypes of careerist women entered the discussion. However, when the interviewees started talking about their family members, or maybe even themselves, who were also postponing childbirth, then instead of 'careerism' other factors were emphasized, such as difficulties in finding the right partner, or financial constraints.

There were many arguments formulated why EVF is problematic, on its disadvantages; these featured strongly in the interviews. One group of arguments was related to reasoning on why postponement of childbearing is problematic. Besides arguments on medical risks (such as higher risk of hypertonia, toxemia during pregnancy, premature birth, miscarriage, etc.), a range of other considerations was brought up in the argumentation against the trend. A recurrent assertion was that the parent should be expected to live at least to the child's age of 18. Another group of arguments included: a certain behavior is needed with children, which comes easier when one is young, it is better psychologically to have a child young, it is not good for the children if the parents are old. It was mentioned that people will look oddly at the parent, parent will be too old to have a grandchild while alive, and that this trend of postponing childbirth is taking society in a wrong direction, it is not "normal".

It is notable how our respondents-who were all working in a profession which interferes with the method of achieving pregnancy allowing those who are infertile to have a child-conceptualized nature in some cases as something ideal, claiming that nature has given the ideal time for child-bearing and that should not be changed:

"It is because for some reason evolution and something... it formed the female organism, and the male one, too, to a certain extent, in a way that there is an ideal time to have children, there is an age when there is a much higher chance to have healthy children, ... there is a reason for that." (M.U.) 
What we see here is the concept of nature used as support for what should be the ideal way. This ties in with what Evernden has observed that the term 'nature' has been used habitually throughout history "to justify and legitimate the actions we wish to regard as normal, and the behavior we choose to impose on each other" (Evernden 1989: 164). Reference to nature often expressed by biologists and health care professionals however is not so evident in the field of assisted reproduction when the very aim of the intervention to improve what nature was allocated to certain infertile couples. Furthermore, there are various speculations on what could be the evolutionary benefit of the menopause in humans, which is by no means general in other species.

Some interviewees also argued against EVF by claiming that if someone resorted to EVF, she will probably raise her child without a father-(the logic was as if she does not find a partner at age 35 and banks her eggs why would she find a partner necessarily later when she has her eggs thawed). It has also been voiced that EVF is impersonal and may lead to a dystopian future with designer babies.

Recurrent arguments against EVF were also related to the efficiency/inefficiency of the technology: that it does not offer 100 percent certainty and that the technology is not efficient enough for certain age groups. It was mentioned that the age group for which it would be effective enough with a high success rate is not thinking yet of employing this procedure. Whilst it was regarded as having a too low success rate for those who were seen to be more likely resort to it more-women over 35.

"Well I do not see its advantages... Those patients, or people, right, for whom this system would work relatively well, those in their early twenties, they are, I believe, in the age when they do not quite think about making a family." (M.K.)

It was also argued that it could happen that if EVF spread it resulted in worsening certain trends in society: that it could lead to a wider spread of careerism amongst women and further postponement of childbirth with giving women a hope of being able to have a child in the future-whilst some of these hopes might not be realized as EVF was not 100 percent method.

Whilst, arguments against EVF were much more frequent, some of our interviewees also articulated some arguments on the positive aspects of EVF. Besides medical arguments (such as that there would be eggs of better quality for EVF, etc.) again nonmedical claims were also mentioned. One argument that appeared several times in the interviews is related to the perspective of reproductive rights. The argument was that women should be able to have the same opportunity as men: men are able to father children at an older age, biologically, and they have the legal possibility in Hungary to freeze and store their sperm. An interviewee even raised the aspect that this latter legal difference is in contrast with the principle of equal opportunity. Still, sometimes arguments for giving the opportunity with EVF were still intertwined with a negative evaluation if a woman wants only to have a child after a certain age. Another interviewee emphasized that people live longer than earlier and also live healthier lives thus it is less of an issue if the parents are older than earlier. 
Although arguments against EVF were more prominent amongst interviewees than arguments for EVF, it is an interesting issue whether these negative attitudes translate into a prohibitive attitude: i.e. whether the interviewees would be favor of placing state restrictions on EVF utilization and how strict they think the restrictions should be, or whether they would think that women themselves who engage with the technology could responsibly make the decisions themselves.

\section{Limiting the Scope of EVF}

Almost all of the interviewees were in favor of certain limitations for use even in case of self-funding of the procedure.

Many respondents mentioned age limits for woman at time of egg extraction. All of them gave 35 as limit-except for one participant who would give 37 . This is notable, as many of the interviewees envisioned EVF being primarily utilized by women over 35so they would prohibit its use even in case of self-funding precisely for the group of women who they argued would most likely want to use it. (And, for example, in the cited 2013 study by Hodes-Wertz et al. the average of women in their sample who took the procedure was 38). Reasoning for drawing the line at 35 often brought in biological aspect: it was asserted that after this age the method was not effective enough.

This raises the issue of who should assess whether a procedure is effective enough or not. In case the state places restrictions on this, it takes away the possibility for the woman herself to be the person who can decide. The same amount of possibility might mean something different for a specialist and for a woman wanting to freeze her eggs. An embryologist, M. K. was not in favor of EVF and one of his objections was that he did not consider the procedure to be effective enough, but still he emphasized that women themselves could evaluate their chances themselves.

I would not fix an age limit. ...For some people even a onepercent chance means a lot while others even with 10 percent chances would not even try. It is essential that patients receive adequate information.Only they themselves can decide what is the chance that someone would still consider worthtrying. (MK)

This view of considering women as competent decision-makers rarely appeared in the interviews in contrast to the paternalistic attitude that dominated the interviewees' discourse. It only surfaced a few times, and those mentioning it mostly were still for placing strict restrictions on EVF which somehow contradicts how seriously they take giving decision-making competence to women. For example, although D.A. at another point in the interview argued that we should treat the woman "as adults" and consider them able to assess the risk and benefits, in the end she chose a restriction to be placed on extraction as 35 years.

Almost all participants mentioned an age limit for the time of the transfer of embryo to the woman's body. Respondents mentioned 40 and 45 years as the limit. The major argument for the age limit at time of transfer was that otherwise the woman would be too old to be a parent and they reiterated the arguments why they felt this would be 
problematic: including health risks for the woman and other reasons. Here, again a paternalistic view is apparent behind some of the arguments: as above a certain age pregnancy might be too risky, it should be prohibited rather than giving the women the possibility to assess the risks and benefits herself and make a decision based on that. It is notable that part of the interviewees would like to see a limit that is stricter even than the current limits for IVF utilization in Hungary. Thus, part of the interviewees in their everyday practice are routinely meeting with clients they regard to be too old to be mothers.

We were also interested in differences in opinions whether interviewees thought differently on the timing of fatherhood, than of motherhood. We asked if they thought that there should be age limitations of male partners in IVF. When asked on age limit for the male partner in case of IVF, some were for no limitations, or less strict limitations, and some for the same age limit as for women. Nobody mentioned that this limit should be stricter than for the mother-even though in other parts of some of the interviews it was an important argument that parents should stay alive while their children reach the age of at least 18, and by some it was also acknowledged that women on average die later than men. Some explicitly argued that the role of the mother is more important, so her age is more important. For long term sperm storage either no age limit was mentioned or less strict limit than for egg storage for women.

"With men, I would say that with men, this limit can be pushed forward, even to sixty. We all know that the fathers of Mozart and Beethoven were elderly men, so children of old men in the arts... Children are raised, especially during their first years, by their mother." (Dr. E.A.)

Respondents were mainly against giving state funding to EVF in the current economic situation of the country - which is notable, as in case of state funding there would likely be more demand for the procedure, which would increase the profit of infertility clinics, where these interviewees were working. Several of them stated that in the country's economic situation what gets state funding needs to be prioritized, and EVFs not such a priority.

Other reasons for wanting to have egg EVF (such as health problems) were rated more positively for state funding. Only a few respondents reacted positively to giving state funding to elective vitrification, and all of them were only in favor in case of restrictions, and they tended to emphasize that health reasons were more legitimate reasons for state funding. Interviewees, who earlier expressed positive attitudes towards EVF, in their argumentation on state-funding tended to give more support to a younger age group utilizing the procedures illustrated in the excerpts below:

"Now, in the case of a 22-year-old girl who is about to undergo chemotherapy, I would give state support, but then with a 38-year-old woman who says, out of whim, that well, let's freeze that egg because it will be better for me to get pregnant at the age of 43 , so then I would not think I gave state support and I definitely put an age limit on it." (G.B.) 
For women to choose EVF, besides it being legally available, another important factor could be having enough knowledge to opt for EVF: whether women are aware of declining egg quality with age or that IVF cannot be a magical answer with one's own eggs to all problems above a certain age if EVF has not been conducted earlier. Many interviewees talked about meeting with many misconceptions from women: that many women who phoned in to the clinic were not aware of their low chances after reaching 40-46 years of age.

The existence of these misconceptions amongst some women also raises the issue what kind of information would be useful to be dispersed on EVF. When the clinics' staff members were asked about this, some instantly argued that it is important that this method should not be advertised, thus they would prefer that a service is not popularized which they provide. And advertisements for EVF could be source of information on age-related infertility issues.

An important argument connected to age was also the issue of efficiency in the interviews. However, it is also worth mentioning that interviewees had a narrow view of efficiency, which was in consonance with their traditional gender views. Other views on rating the efficiency of EVF also exist, for example, Mesen et al. (2015) argue based on their decision tree models that although birth rate is maximized if the woman has egg extraction before the age of 34, the relative benefit of EVF compared to not doing anything is maximized at the age of 37 (greatest improvement in the likelihood of birth compared to no action). In contrast, there was little benefit to cryopreserving eggs in the 20 s, as probably many women would not need these eggs. According to their model, even at the age of 38 or 39 it is beneficial to turn to EVF as compared to no actionalthough, of course, at that age there is a much less chance of getting a baby from the procedure, compared to the eggs being vitrified at an earlier age.

Most of the interviewees could only imagine more senior women using the procedure. In general they were against advertisements and wider information dissemination on EVF within society, as they felt this might lead to an ever greater postponement of childbirths on the level of society. In fact some studies have found that the average age of starting EVF is above 35 (Hodes-Werts et al. 2013, Stoop et al. 2014.), this does not mean that it has to stay like this in the future, in case for example more information will be given to societies about age-related infertility and EVF. Gendered medical paternalism creates also a vicious circle: if information is retained because of the fear of 'delayed pregnancy', then less information will be known about age-related infertility. As a result, women face this problem at a more advanced age, while they should be informed about these possibilities at a younger age. In our research the respondents claimed that they would have undergone the procedure earlier if they had had more information earlier. If due to their gender bias or other reasons doctors do not inform women in time, this could actually result in a later use of EVF, thus serving as a self-fulfilling prophecy and infringe women's reproductive rights. One should also consider that, according to a recent survey, women who consider vitrifying their eggs do not aim to buy extra decades for allowing them to have children, but to just a few extra 
years, putting responsible pregnancy's upper age limit to be the early years of the fourth decade (Stoop et al. 2011).

\section{Conclusions}

We argue that motivated by pronatalism (which is a widely shared value in Hungarian society) gender biases and the retention of information on the option and possibilities of vitrification constitutes a special form of medical paternalism that we call gendered medical paternalism. In this case, the motivation is not only to save patients from harmful consequences but also to prioritize alleged public interests, such as increasing the number of births, over women's reproductive choices, which should therefore be controlled by medical professionals. So it is precisely patient's gender that triggers paternalism: to act on behalf of society and not on behalf of her. Instead of providing access to good quality information on the efficacy of the egg cryopreservation and pregnancy in a certain age the tactic is rather to conceal relevant information and preventing choice. In case of assessing EVF, one could see that opinions expressed by medical doctors and health care workers of the in vitro clinics were based not only on the technical elements such as efficiency and safety of the procedure but were intertwined with vague and often biased expectations on women's lifestyle. Many opinions showed the elements of the slippery slope arguments and reference to women's irresponsible behavior in field of reproduction. Even in the lack of acceptable alternative, the delaying pregnancy was ultimately regarded as an egoistic choice.

Elements of the gendered medical paternalist attitude identified in our sample of IVF staff included: the conceptualization of EVF not as a choice to have a child, but as a decision not to have a child at a time point which is considered proper, traditional gender attitudes regarding women and career, negative careerist stereotypes of women engaging with the technology, arguments that for a man it is all right to become father at a later age, conservative attitudes toward ideal time of giving birth supported by claims to biology and nature, women not seen as competent decision-makers in the field of reproduction, favoring strict restrictions to be placed on EVF supposedly in the interests of the women herself, or the potential child, or of society itself.The strict restrictions that were favored were by the clinicians in our sample were upper age limit for egg extraction to be 35 , and for the transfer of the embryo some were for age 40 , others 45 for the age of the women.

The right for proper information on EVF is needed for securing women's reproductive rights. Informed consent and unbiased information is needed to insert vitrification for the purposes of future reproduction among the already accepted reproductive technologies. Subject to honestly surveying the success rates, we argue that in Hungary the vitrification of human eggs should be permitted, not only in the case of certain diseases but also when a woman would like to have a child but she does not have an eligible partner at the time her eggs are frozen, and she plans to bear a child together with her future partner or, for ethical reasons, she does not want to risk the possible disposition of a frozen embryo. It is important also for the physicians to offer 
information about the chances of success after vitrification and thawing as well as of the fact that egg vitrification means no guarantee for the success of future pregnancy as to facilitate informed decisions by the patients.

This type of "ovarian reserve" may be very helpful for those who are still looking for their partner or who are not yet ready for maternity. The most serious doubts are related to the fact that by supporting the practice of vitrification, one may suggest the false idea that this is a simple, routine technology with a guaranteed successful outcome. In reality, it would be overoptimistic or even misleading to think that it is enough to "thaw, mix, and implant" the egg and the baby is almost ready-made. Not so long ago, in 2008, the American Society for Reproductive Medicine (ASRM) still designated egg cryopreservation as an experimental procedure. Although there has been significant technological development since then, vitrification is still not more than a doubtful chance for the hibernation of maternity. And even if egg vitrification becomes cheaper and more efficient in the future, one should not fear that this practice becomes so widespread that it supersedes natural reproduction. It is simply a chance for women to become mothers later in their life. Needless to say that using eggs for purposes of reproduction still depends on the woman's age and her general and reproductive health conditions. Egg vitrification for non-medical purposes would provide women with a little extra time and some added hope for reproduction with their partners.

More importantly, we found that existing hidden biases that relate to women's bodies and their expected traditional roles in society distort medical attitudes as well as the content of informed consent, or the retention of information on the possibility of cryopreservation. This bias should be recognized in order to proceed with a better policy to EVF and better quality of the informed consent in the field of cryopreservation of the eggs.

\section{Acknowledgements}

This article is based on the research conducted within the framework of the NKI/OTKA research project 108981. Lilla Vicsek's work was supported by a Bolyai János Research Fellowship.

\section{Literature}

Baldwin, Kylie, Lorraine Culley, Nicky Hudson, and Helene Mitchell (2014) Reproductive Technology and the Life Course: Current Debates and Research in Social Egg Freezing.Human Fertility, vol. 17, no. 3, 170-179.

Bernstein, Stephanie and Claudia Wiesemann (2014) Should Postponing Motherhood via "Social Freezing" Be Legally Banned? An Ethical Analysis. Laws, vol. 3, no. 2, 282-300.

Boldt, Jeffrey (2011) Current Results with Slow Freezing and Vitrification of the Human Oocyte. Reproductive BioMedicine Online, vol. 23, no. 3 (September 2011), 314-322.

Braun, Virginia and Victoria Clarke (2006) Using Thematic Analysis in Psychology. Qualitative Research in Psychology, vol. 3, no. 2, 77-101. 
Cattapan, Alana, Kathleen Hammond, Jennie Haw, and Lesley A. Tarasoff (2014) Breaking the Ice: Young Feminist Scholars of Reproductive Politics Reflect on Egg Freezing. IJFAB: International Journal of Feminist Approaches to Bioethics, vol. 7, no. 2 (Special Issue on Transnational Reproductive Travel, Fall 2014), 236-247.

Dworkin, Gerald (1976) Paternalism. In Samuel Gorovitz, Ruth Macklin, Andrew L. Jameton, John M. O'Connor, and Susan Sherwin (eds.), Moral Problems in Medicine (Englewood Cliffs, NJ; Prentice-Hall, 1976), pp. 185-200.

Dondorp, Wybo, Guido de Wert, Guido Pennings, Francoise Shenfield, Paul Devroey, Basil C. Tarlatzis, Pere N. Barri, and Klaus Diedrich from ESHRE Task Force on Ethics and Law (2012) Oocyte Cryopreservation for Age-Related Fertility loss. Human Reproduction, vol. 27, no. $5,1231-1237$.

Evernden, Neil (1989) Nature in Industrial Society. In Ian H. Angus and Sut Jhally (eds), Cultural Politics in Contemporary America. New York: Routledge, 151-164.

Goold, Imogen and Julian Savulescu (2009) In Favor of Freezing Eggs for Non-Medical Reasons. Bioethics, vol. 23, no. 1, 47-58.

Gossett, D. R., Nayak, S., Bhatt, S., \& Bailey, S. C. (2013). What do healthy women know about the consequences of delayed childbearing?.Journal of health communication, 18(sup1), 118-128.

Hodes-Wertz, Brooke, Sarah Druckenmiller, Megan Smith, and Nicole Noyes (2013) What Do Reproductive-Age Women Who Undergo Oocyte Cryopreservation Think about the Process as a Means to Preserve Fertility? Fertility and Sterility, vol. 100, no. 5, 1343-1349.

Inhorn, Marcia C. (2013) "Women, Consider Freezing Your Eggs." CNN.com, April 9, 2013. Available at http://www.cnn.com/2013/04/09/opinion/inhorn-egg-freezing (last accessed on March 31, 2017).

Hashiloni-Dolev, Yael, Amit Kaplan, and Shiri Shkedi-Rafid (2011). The Fertility Myth: Israeli Students' Knowledge Regarding Age-Related Fertility Decline and Late Pregnancies in an Era of Assisted Reproduction Technology. Human reproduction, vol. 26, no. 11, 3045-3053.

Keglovits, B. (2015): A social egg freezing és a munkaerő-piaci nemegyenlőtlenség kapcsolata. Masters Thesis. Corvinus University, Budapest

Lallemant, C., Vassard, D., Nyboe Andersen, A., Schmidt, L., \&Macklon, N. (2016). Medical and social egg freezing: internet-based survey of knowledge and attitudes among women in Denmark and the UK. Acta obstetricia et gynecologica Scandinavica, vol. 95, no. 12, 14021410.

Lewis, E. I., Missmer, S. A., Farland, L. V., \& Ginsburg, E. S. (2016). Public Support in the United States for Elective Oocyte Cryopreservation. Fertility and Sterility, vol. 106, no. 5, 11831189.

Liu, Kimberly E. and Ellen M. Greenblatt (2012) Oocyte Cryopreservation in Canada: A Survey of Canadian ART Clinics. Journal of Obstetrics and Gynecology Canada, vol. 34, no. 3, 250-256.

Mac Dougall, Kirstin, Yewoubdar Beyene, and Robert D. Nachtigall (2013) Age Shock: Misperceptions of the Impact of Age on Fertility before and after IVF in Women who Conceived after Age 40. Human Reproduction, vol. 28, no. 2, 350-356.

Martin, Lauren Jade (2010) Anticipating Infertility: Egg Freezing, Genetic Preservation, and Risk. Gender and Society, vol. 24, no. 4, 526-545.

Mertes, Heidi and Guido Pennings (2011) Social Egg Freezing: For Better, not for Worse. Reproductive Biomedicine Online, vol. 23, no. 7 (December 2011), 824-829.

Mesen, T. B., Mersereau, J. E., Kane, J. B., \& Steiner, A. Z. (2015).Optimal timing for elective egg freezing. Fertility and sterility, vol. 103, no. 6, 1551-1556. 
Mohapatra, Seema (2014) Using Egg Freezing to Extend the Biological Clock: Fertility Insurance or False Hope? Harvard Law and Policy Review, vol. 8, no. 2, 381-411.

Organisation for Economic Co-operation and Development (OECD) (2016): OECD Family Database, Indicator SF2.1, "Fertility Rates". Available at https://www.oecd.org/els/family/SF 21 Fertility rates.pdf, last accessed on March 31, 2017.

Paksi, V., \& Ivett Szalma (2009) Age Norms of Childbearing. Early, Ideal and Late Childbearing in European Countries. Review of Sociology of the Hungarian Sociological Association, 2, 57-80.

Papadopoulou, Lina (eds) (In)Fertile Citizens Anthropological and Legal Challenges of Assisted Reproduction Technologies. Athens: Alexandria Publications, 23-39.

Patrizio, P., Molinari, E., \& Caplan, A. (2016). Ethics of medical and nonmedical oocyte cryopreservation. Current Opinion in Endocrinology, Diabetes and Obesity, 23(6), 470-475.

Sándor, Judit (2014) Hibernált anyaság, avagy mit tehet a sejt? Magyar Narancs 2014/47. Available in Hungarian at http://magyarnarancs.hu/egotripp/hibernalt-anyasag-avagy-mittehet-a-sejt-92678

Scharle, Á. (2015). Attitudes to gender roles in the Czech Republic, Hungary and Poland. Budapest Institute and Institute of Economics, Hungary.

Sobotka, T. (2004) Postponement of Childbearing and Low Fertility in Europe. Doctoral Thesis: University of Groningen.

Schuman, L., Witkin, G., Copperman, K., \& Acosta-La Greca, M. (2011). Psychology of egg freezing patients: would they consider single motherhood? Fertility and Sterility, vol. 96, no. 3, Suppl., S206.

Schuman, L., Witkin, G., Copperman, K., Acosta, M., Barritt, J., \& Copperman, A. (2012). Women Pursing Non-Medical Oocyte Cryopreservation Share Information About Their Treatment with Family and Friends. Fertility and Sterility, vol. 97, no. 3, Suppl., S12-S13.

Soliman, H. H., Khaki, A. A., Al-Azawi, T., \& Al-Hasani, S. (2012). Oocyte Cryopreservation, Will It Be a Real Social Choice and Family Solution? Middle East Fertility Society Journal, vol. 17, no, 1, 8-11.

Stoop, Dominic, Julie Nekkebroeck, and Paul Devroey (2011) A Survey on the Intentions and Attitudes towards Oocyte Cryopreservation for Non-Medical Reasons among Women of Reproductive Age. Human Reproduction, vol. 26, no. 3 (March 2011), 655-661.

Stoop, Dominic, Fulco van der Veen, Michel Deneyer, Julie Nekkebroeck, and Herman Tournaye (2014) Oocyte Banking for Anticipated Gamete Exhaustion (AGE) Is a Preventive Intervention, Neither Social, Nor Nonmedical. Reproductive BioMedicine Online, vol. 28, no. 5 (May 2014), 548-551.

Stoop, Dominic, Elise Maes, Nikolaos P. Polyzos, Greta Verheyen, Herman Tournaye, and Julie Nekkebroeck (2015) Does Oocyte Banking for Anticipated Gamete Exhaustion Influence Future Relational and Reproductive Choices? A Follow-Up of Bankers and Non-Bankers. Human Reproduction, vol. 30, no. 2 (February 2015), 338-344.

Szalma, Ivett (2010). Attitűdök a házasságról és a gyermekvállalásról [Attitudes towards Marriage and Childbearing]. Demográfia, vol. 53, no. 1, 38-66.

Szalma, Ivett and Judit Takács (2016) Gyermektelenség Magyarországon: Mítoszok és kutatási eredmények [Childlessness in Hungary: Myths and Research Results]. Magyar Tudomány, vol. 177, no. 2 (February 2016), 159-167.

Tan, Shu Qi, Andy Wei Keat Tan, Matthew Sie Kuei Lau, Heng Hao Tan, Sadhana Nadarajah (2014) Social Oocyte Freezing: A Survey among Singaporean Female Medical Students. Journal of Obstetrics and Gynaecology Research, vol. 40, no. 5, 1345-1352. 
The Practice Committee of the American Society for Reproductive Medicine and The Society for Assisted Reproductive Technology (2013) Mature Oocyte Cryopreservation: A Guideline. Fertility and Sterility, vol. 99, no. 1, 37-43,

Vallejo, V., J. A. Lee, L. Schuman, G. Witkin, E. Cervantes, B. Sandler, and A. B. Copperman (2013) Social and Psychological Assessment of Women Undergoing Elective Oocyte cryopreservation: A Seven-Year Analysis. Open Journal of Obstetrics and Gynaecology, 3, 17.

Vicsek, L. (2017): Fertility myths, technology myths and their sources - Lay reasoning on agerelated fertility decline. Budapest: manuscript.

Waldby, Catherine (2015) 'Banking Time': Egg Freezing and the Negotiation of Future Fertility. Culture, Health, and Sexuality, vol. 17, no. 4, 470-482.

Wennberg, Anna-Lena, Kenny A. Rodriguez-Wallberg, Ian Milsom, and Mats Brännström (2016) Attitudes towards New Assisted Reproductive Technologies in Sweden: A Survey in Women 30-39 Years of Age. Acta Obstetricia et Gynecologica Scandinavica, vol. 95, no. 1, 38-44.

Witkin, Georgia, Ann Tran, Joseph A. Lee, Lisa Schuman, Lawrence Grunfeld, and Jaime M. Knopman (2013) What Makes a Woman Freeze: The Impetus behind Patients' Desires to Undergo Elective Oocyte Cryopreservation. Fertility and Sterility, vol. 100, no. 3, S24.

Yu, L., B. Peterson, Marcia C. Inhorn, J. K. Boehm, and P. Patrizio (2016) Knowledge, attitudes, and intentions toward fertility awareness and oocyte cryopreservation among obstetrics and gynecology resident physicians. Human Reproduction, vol. 31, no. 2, 403-411. 